\title{
CORTESANA, HETAIRA: LA HEROÍNA FILÓSOFA DE SADE
}

Courtesan, Hetaira: Sade's heroine philosopher

\author{
NATALIA L. ZORRILLA \\ Universidad de Buenos Aires-CONICET(Argentina) \\ n.zorrilla@conicet.gov.ar
}

Resumen

Este artículo se propone examinar la caracterización ficcional de la mujer filósofa durante el siglo XVIII, concentrándose en la novela Histoire de Juliette, ou les prospérités du vice de Donatien Alphonse François de Sade. Sostendremos como hipótesis que las heroínas filósofas (personificadas en las mujeres libertinas) de Histoire de Juliette se habrían construido a base de la exaltación de la figura de la hetaira de la Grecia Clásica. Analizaremos dos referencias a las hetairai que aparecen en la obra: la caracterización de Clairwil, una de las tutoras libertinas de Juliette, y la participación de Aspasia, Phryné y Lais como parte del séquito de libertinas de la protagonista de la novela.

Palabras clave: Sade; Hetaira; historia de Juliette; mujeres filósofas.

Abstract

This article aims at examining the fictional characterization of women philosophers during the eighteenth century, focusing on Donatien Alphonse François de Sade's novel, Histoire de Juliette, ou les prospérités du vice. We seek to show that the marquis's heroines philosophers (personified by libertine women) in Histoire de Juliette are modeled after the figure of the hetaira in Classical Greece. We analyze two sets of references to the hetairai that appear in the aforementioned novel: the description of Clairwil, one of Juliette's libertine tutors and partners, and the participation of Aspasie, Phryné and Lais in Juliette's libertine entourage.

Key words: Sade; Hetaira; histoire de Juliette; women philosophers.

\section{INTRODUCCIÓN}

La caracterización que Donatien Alphonse François de Sade (1740-1814) ofrece de la mujer y de su sexualidad a lo largo de su obra no ha cesado de suscitar interés entre sus intérpretes. En el marco del \#MeToo movement (o en su versión francesa, \#BalanceTonPorc), el debate se ha reavivado tanto en la prensa escrita ${ }^{1}$ como en las

\footnotetext{
${ }^{1}$ En el foro actual de la opinión pública, la actriz Catherine Deneuve expresó sus reservas respecto de la oleada de denuncias por acoso y abuso sexual y sexista surgida de los movimientos mencionados, en favor de preservar ciertos rituales de "seducción". Para Deneuve, la cuestión de si debemos denunciar o no a los acosadores es análoga a la de si se debe o no "quemar" (censurar) a Sade. En este nuevo contexto, ha reactivado entonces la Recibido: 13 mayo, 2020 Aceptado: 8 julio, 2020
} 
publicaciones académicas y ensayos que se pronuncian acerca del legado de Sade. El conocido marqués se ha convertido en una figura histórica insoslayable para explicar la cultura sexo-afectiva francesa ${ }^{2}$, tanto para quienes quieren hacer de él un defensor de la libertad sexual de la mujer como para quienes lo leen como un autor que contribuyó a perpetuar, a través de su obra pornográfica y de sus crímenes sexuales, la misoginia y la cultura de la violación (rape culture) ${ }^{3}$. En el seno del feminismo, esta discusión se dio, por ejemplo, entre Angela Carter [1978] (2001) y Andrea Dworkin(1979), representantes de la primera y la segunda postura respectivamente.

El esfuerzo reciente de las comentadoras de Sade se ha abocado en particular a la lectura cercana de su obra y de su epistolario, y a la apreciación de los matices históricos, literarios y filosóficos que este corpus comporta. Si bien la justificación conceptual de la inferioridad del sexo femenino abunda en la obra esotérica ${ }^{4} \mathrm{de} \mathrm{Sade}^{5}$, la mayoría de sus protagonistas libertinas las desautorizan a través de sus propias filosofías y las desacatan a través de sus propias acciones. Esta es la valoración que hace las veces de hilo conductor del volumen Sade et les femmes. Ailleurs et autrement (2013/2014) de Itinéraires. Más apologético ha sido el tono de Marie-Paule Farina en su libro Sade et ses femmes (2016), en el que la autora se dedica a resaltar los momentos afectuosos entre este y, por ejemplo, su esposa, teniendo en cuenta también sus intercambios con otras figuras femeninas en su vida. Farina ha publicado asimismo Le rire de Sade (2019), en esta misma línea de "rescate" de Sade (de hecho, llama a la segunda parte del libro "Apologie de Sade"). Su primera parte se titula "Femmes, encore un effort pour devenir sadiennes", evocando el panfleto de la Quinta Parte de Philosophie dans le boudoir, "Français, encore un effort si

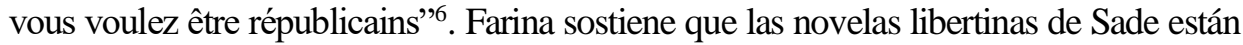
sobre todo dirigidas a un público femenino. Según esta intérprete, a través de la exaltación de la liberación sexual de Juliette, guiada por sus instructoras amantes, Sade propugna modelos de feminidad sagaces y rupturistas y revela lo grotesco del acomodaticio y estático poder masculino.

Nuestro aporte a la discusión acerca de la caracterización de la mujer en Sade, en particular la de la mujer filósofa, busca evidenciar la importancia de la recepción de la

pregunta que se hacía la filósofa feminista Simone de Beauvoir [1955] (1972), en Faut-il brûler Sade? Véase Deneuve (2018).

${ }^{2}$ Véase Heynders (2017); Har-Peled (2018); Condomines (2019).

${ }^{3}$ Para examinar una de las formulaciones originales del concepto de rape culture, véase Herman (1978).

${ }^{4}$ La distinción establecida por Michel Delon entre textos esotéricos y exotéricos dentro del corpus sadeano (Sade, 1990, pp. ix-lviii) apunta a poder diferenciar los escritos clandestinos, usualmente libertinos, crueles y obscenos de Sade de sus obras "oficiales", más “decorosas".

${ }^{5}$ Véase, por ejemplo, el discurso de Belmor en Histoire de Juliette (Sade, 1998, pp. 632-3).

${ }^{6}$ En un sentido diametralmente opuesto al de Farina, Luce Irigaray (1977) escribe: Françaises, ne faites plus un effort, desde la perspectiva de las sobrevivientes de los horrores sádicos.

142 | AlPHA No 53 (Diciembre 2021) PÁGS. 141-152. ISSN 07 16-4254 
Antigüedad Clásica en el pensamiento del marqués. Concentrándonos en la novela libertina Histoire de Juliette, ou les prospérités du vice (1801), sostendremos como hipótesis que las heroínas filósofas en esta obra se habrían construido a base de la exaltación de la figura de la hetaira de la Grecia Clásica, en el marco de la rehabilitación de la cultura grecorromana propugnada por el movimiento ilustrado, al que pertenecería Sade.

En efecto, si los personajes de las filósofas en la obra esotérica de Sade constituyen emblemas de la liberación sexual femenina, es debido a su constante combate teórico y práctico contra los prejuicios, actitud que las lleva a adoptar como modo de vida los principios que se siguen de las reflexiones teóricas ilustradas (siendo Juliette además una lúcida interlocutora en debates políticos).

Analizaremos entonces dos referencias a las hetairai que aparecen en Histoire de Juliette: la caracterización de Clairwil, una de las tutoras libertinas de Juliette, y la participación de Aspasia, Phryné y Lais como parte del séquito de libertinas que acompaña a Juliette en las orgías que esta organiza en el tramo final de la novela. Las referencias veladas o explícitas a personalidades como Aspasia, Phryné y Lais promueven cierta legitimación de distintos espacios sexoafectivos que se abrirían por fuera del matrimonio heteromonogámico, a la vez que descubren figuras de mujeres autónomas que integraban los mismos círculos intelectuales que sus compañeros varones.

\section{CLAIRWIL}

"Era alta, digna de ser pintada (...) En una palabra, era el porte de Minerva con los atractivos de Venus" (Sade, 2009, p. 216) ${ }^{7}$ : así describe Juliette a Mme. de Clairwil, quien sería su compañera, mentora, amante y cómplice por los próximos años, al verla por primera vez ${ }^{8}$. Dice: "Clairwil forma parte de un eximio grupo de mujeres libertinas: su sabiduría filosófica traspasa la mera vulgarización del epicureísmo hegemónico en los sectores más acomodados del Antiguo Régimen, a partir del cual se buscaba justificar la "buena vida" de los placeres sensoriales". Por el contrario, Clairwil es quien inculca en Juliette los principios de su filosofía libertina materialista y atea, enseñándole a su discípula, mediante su ejemplo, cómo deben integrarse los aspectos teóricos o intelectuales de este saber con los prácticos, en lo puntual eróticos.

A estas gracias imperiosas, Madame de Clairwil unía una inteligencia muy elevada; era muy instruida, singularmente enemiga de los prejuicios..., que había arrancado de sí en la infancia; era difícil que una mujer llevase la filosofía más lejos. Por otra parte, tenía muchos talentos: hablaba perfectamente el inglés y el italiano;

\footnotetext{
${ }^{7}$ Elle était grande, faite à peindre; (...) c'était, en un mot, la taille de Minerve, sous les agréments de Vénus (Sade, 1998, p. 418).

${ }^{8}$ Para un análisis detallado de este personaje de Histoire de Juliette, ver Castro (2013).
} 
representaba comedias como un ángel; danzaba como Terpsícore; sabía química, física; hacía bonitos versos; dominaba la historia, el dibujo, la música, la geografía (Sade, 2009, pp. 216-217) .

Clairwil poseía todos los talentos y las habilidades necesarias para desempeñarse de manera satisfactoria en los círculos sociales de mayor poder socioeconómico. De origen noble, su formación y preparación para el universo de la galantería y la seducción parecería inspirarse en la de las hetairai griegas.

Casi siempre traducido como "cortesana", el término hetaira no refleja de manera clara las cualidades atribuidas a aquellas, producto de la extrapolación que pretendería unir sin fisuras dos contextos culturales distintos y lejanos en el tiempo. "Se trata además de un término ambiguo, que sufre desplazamientos conceptuales a lo largo de los siglos y que nos llega sobre todo por medio de textos polémicos, algunos de los cuales aportan cierta carga peyorativa al mismo"10.

En la Grecia Clásica ${ }^{11}$, se solía distinguir entre las hetairai, las prostitutas (pornai), las concubinas (pallakai), y las "legítimas" esposas. Mientras que estas últimas tenían la función de generar la descendencia legítima de sus esposos, las figuras restantes se asociaban antes bien al placer, a la agradable compañía o a actividades sexuales purgativas. De manera tradicional, los/as intérpretes han caracterizado a las hetairai como prostitutas de alto nivel (Dillon, 2003; Pomeroy, 1975; Gilhuly 2009), instruidas en el arte de la conversación, y que participaban en los simposios, además de poseer talento para la danza y la música y, en algunos casos, una extraordinaria belleza física. Las pornai, en cambio, prostitutas comunes de estratos menos privilegiados, salen menos favorecidas en sus caracterizaciones.

Sin embargo, algunos/as comentadores/as (Kennedy, 2015) no acuerdan con la idea de que la hetaira haya sido solo una prostituta o una cortesana en el sentido moderno del término, ya que muchas de las llamadas hetairai eran mujeres libres (de nacimiento o esclavas libertas), en su mayoría extranjeras, que pertenecían al mundo de los estratos más privilegiados. Hetaira se decía entonces en muchos sentidos: podía también aludir a

\footnotetext{
${ }^{9}$ À ces grâces impérieuses, Mme de Clairwil joignait un esprit très élevé; elle était fort instruite, singulièrement ennemie des préjugés... déracinés par elle dès l'enfance, il était difficile à une femme de porter la philosophie plus loin; d'ailleurs beaucoup de talents, sachant parfaitement l'anglais et l'italien, jouant la comédie comme un ange, dansant comme Terpsichore, chimiste, physicienne, faisant de jolis vers, possédant bien l'histoire, le dessin, la musique, la géographie (Sade, 1998, p. 418).

${ }^{10}$ Uno de estos textos polémicos es el llamado Contra Neera, atribuido a Demóstenes o a veces a PseudoDemóstenes y pronunciado por Apolodoro, el acusador de la hetaira. Para una contextualización y una presentación del Contra Neera, ver García Garino (2009).

${ }^{11}$ Nos referimos al período de la historia de la civilización griega comprendido entre el término de la época arcaica (la revuelta de Jonia, 499 a. C.) y el comienzo de la época helenística, coincidente con el comienzo del reinado de Alejandro Magno (336 a. C.-323 a. C.). Comprende el siglo V y el IV a. C.
}

144 | AlPha № 53 (DiCIEMBRE 2021) PÁGS. 141-152. ISSN 07 16-4254 
aquellas mujeres que no tenían una dote o que por otras circunstancias (por ejemplo, no ser originarias de Atenas) no podían casarse legalmente. El término se había utilizado en siglos previos asimismo como sinónimo de hetairoi o compañero, tal como vemos en Safo, que se refiere a su propio círculo de amigas como hetairai (fr. 142, poema 160). De manera que la palabra hetaira podría haber designado solo a ciudadanas o mujeres de elite que participaban en simposios y llevaban una vida de lujos, tal como sus contrapartes masculinas (durante los siglos VI y V a. C. [Kennedy, 2015]), y que, debido a su status de no casadas o "no casables", fueron por ello sexualizadas. Esta caracterización de la hetaira se adecua sobre todo al perfil que Sade va construyendo de Clairwil a lo largo de la novela.

En efecto, Clairwil irrumpe en Histoire de Juliette como la personificación de la autonomía femenina, autonomía que inspirará a su discípula. Su "orgullo insoportable" y su desprecio y odio hacia los varones cercenó cualquier lazo de dependencia emocional respecto de estos, permitiéndole desarrollar una "feliz apatía" (Sade, 1998, p. 421). Clairwil contaba con todas las herramientas para complacerlos, herramientas que le permitían seducirlos y luego torturarlos y sacrificarlos en los crueles simposios orgiásticos que organizaba con sus amistades libertinas, o cuando menos establecer una complicidad criminal con los participantes varones en tanto le proveyeran víctimas para estos festivales libertinos.

Su autonomía, no obstante, no es un mero rasgo de su personalidad, surgido de manera azarosa por su historia de vida, sino que es el resultado de su meditada filosofía, a la que Juliette denomina "estoicismo feliz" (Sade, 1998, p. 784). La cosmovisión materialista y atea de Clairwil la lleva a concebir el universo de forma amoral y a plantear, en consecuencia, la equipolencia entre vicio y virtud, a los que a su vez redefine en términos fisiológicos: al primero lo entiende como la sensibilización o la inclinación determinante de un cuerpo hacia placeres intensos, vinculados a la transgresión y al crimen; a la segunda, en cambio, como la predisposición hacia placeres más sutiles, vinculados a la observancia de las normas. Cada cuerpo individual sería, a causa de su particular organización fisiológica, sensible o bien a los placeres criminales o bien a los placeres tenues:

La sensibilidad, querida, es el hogar de todos los vicios, como lo es de todas las virtudes (...). Esta sensibilidad, puramente física, depende de la conformidad de nuestros órganos, de la delicadeza de nuestros sentidos y, más que nada, de la naturaleza del fluido nervioso, en el que yo sitúo generalmente todos los afectos del hombre (Sade, 2009, p. 220) ${ }^{12}$.

\footnotetext{
${ }^{12}$ La sensibilité, ma chère, est le foyer de tous les vices, comme elle est celui de toutes les vertus (...). Cette sensibilité purement physique, dépend de la conformité de nos organes, de la délicatesse de nos sens, et plus que tout de la nature du fluide nerval, dans lequel je place généralement toutes les affections de l'homme (Sade, 1998, pp. 421-2).
} 
Hay, no obstante, otros factores que contribuyen a afianzar o a debilitar estas inclinaciones: la educación y el hábito. Por medio de ellos, según Clairwil, puede alcanzarse cierto grado de apatía (que es a la vez física y emocional, es decir, anempática), apatía que le permite al sujeto en cuestión tomar pleno control de sí mismo/a. Pero el objetivo de esta ascesis apática no consiste en la aniquilación o la represión de las pasiones, sino en poder actuar fría y calculadamente en vistas al cumplimiento de esos deseos y esas inclinaciones predeterminadas. "Estos son, Juliette, los principios que me han llevado a esta tranquilidad, a este reposo de las pasiones, a este estoicismo que me permite ahora hacer y soportar todo sin emoción" (Sade, 2009, p. 224) $)^{1314}$.

Así, a pesar de no ser ni prostituta ni cortesana más que por contingencia o por diversión, Clairwil ocupa un rol similar al de la hetaira griega, que disfruta de los banquetes interviniendo con sus discursos y apreciaciones y explorando diversas aristas de su erotismo libertino. Más aún, lo que se destaca en ella sobre todo es su búsqueda filosófica por alcanzar la enkráteia (poder sobre sí, ¿empoderamiento?) en esta versión quizás paródica o subvertida del estoicismo que despliega en Histoire de Juliette.

Las aventuras de Clairwil y Juliette van desencadenando sutiles cambios en el vocabulario galante que se utiliza para describir estas orgías asesinas que realizan. Al comienzo de Histoire de Juliette, nos encontramos con un uso en apariencia metafórico de este vocabulario, que luego se irá de forma progresiva literalizando. A su vez, las marcas culturales de la Antigüedad Clásica irán colmando cada vez más el relato, proceso que se dispara al trasladarse Juliette a Italia; este desplazamiento espacial equivaldría también, desde nuestro punto de vista, a uno temporal, registrándose así un retroceso simbólico hacia el pasado de la humanidad a medida que avanza la novela.

En efecto, en las descripciones de las primeras orgías de Histoire de Juliette, abundan los eufemismos y las frases alusivas a propósito del "culto a Venus". Pero luego se tornan algo más que una mera "expresión galante", ya que el saber mitológico proveniente de la cultura grecorromana comienza a incidir en cómo se organizan las orgías, esto es: se busca personificar en ellas a tal o cual deidad, asignando distintos roles a cada uno de los participantes. De la teatralización de los ritos sacrificiales y las figuras mitológicas grecorromanas pasamos, a continuación, hacia la dudosa aparición de estas deidades, es decir, a la confusión sensorial o a la afectación de la percepción. Por último, esta obra de Sade termina con la muerte de Justine, la hermana virtuosa de Juliette, quien

\footnotetext{
${ }^{13}$ Voilà, Juliette; voilà les principes qui m'ont amenée à cette tranquillité... à ce repos des passions... à ce Stoïcisme qui me permet maintenant de tout faire, et de tout soutenir sans émotion (Sade, 1998, p. 426).

${ }^{14}$ Para un análisis exhaustivo de este estoicismo libertino, ver Kalouche (2001).

146 | Alpha No 53 (Diciembre 2021) PÁGS. 141-152. ISSN 07 16-4254
} 
fallece atravesada por un rayo que invocan los libertinos luego de haberla arrojado a la intemperie inmolándola a la Naturaleza (¿o a Zeus? $)^{15}$.

\section{ASPASIA, PHRYNÉ, LAIS, TEODORA}

En la escena previa a la anteúltima orgía de la novela, Juliette nos presenta a sus "mujeres", a sus amantes y ayudantas sexuales: "A mi alrededor tenía a cuatro de mis más bellas mujeres: Phryné, Laïs, Aspasie y Théodore; las cuatro de dieciséis a dieciocho años y más hermosas que Venus (...). Por favor, mis bellas amigas, poned en práctica todo lo que sabéis; utilizad todos vuestros refinamientos..." (Sade, 2009, pp. 948-9) ${ }^{16}$.

La fuente de Sade aquí sería, según Michel Delon (el editor de Sade en la Bibliothèque de la Pléiade), la obra Fêtes et courtisanes de la Grèce (1801) de M. Chaussard ${ }^{17}$. Chaussard se aboca a ennoblecer la figura de la hetaira, examinando sus matices y encarnaciones. Establece una distinción entre cinco clases de hetairai o cortesanas. Las primeras eran las filósofas y poetas: Aspasia, Leontina, Safo. La segunda clase está integrada por las favoritas o las amantes de los reyes u hombres célebres: Tais, Herpilis. Una tercera clase está constituida por las "familiares", es decir, aquellas con las que los varones vivían durante un cierto período: Lais, Phryné. El cuarto grupo lo conformaban las aulétrides, las flautistas (ej: Lamia). Y por último, las quintas eran las dictériades, las prostitutas vulgares como Astra.

El cuarteto de hetairai que rodea a Juliette en esta última etapa del relato se compone de dos figuras políticamente influyentes, excelsas en el arte de gobernar, Aspasia ${ }^{18}$ y Teodora, y dos de proverbial belleza, Lais (de Corinto), amante y compañera del filósofo hedonista Aristipo, y Phryné ${ }^{19}$, modelo del escultor Praxíteles. Tanto Phryné

\footnotetext{
${ }^{15}$ Jean-Christophe Abramovici (1995) argumenta que ese rayo que atraviesa a Justine podría interpretarse, en el marco del materialismo ateo libertino sadeano, como un evento solo natural, hasta aleatorio, o bien como una agresión mortal perpetrada por el mismo Júpiter (Zeus) hacia la devota cristiana.

${ }^{16}$ J'avais, autour de moi, quatre de mes plus belles femmes, Phryné, Lais, Aspasie et Théodore; toutes quatre de seize à dix-huit ans, et plus belles que Vénus (...). De grâce, mes belles amies, mettez en usage tout ce que vous savez; usez de toutes vos recherches. (Sade, 1998, pp. 1240-2).

${ }^{17}$ A su vez, Chaussard aduce que los siguientes autores escribieron obras sobre las hetairai, muchas de estas se han perdido: Gorgias, Ammonius, Antiphane, Apollodore, Aristophane, Nicénète de Samos ou d'Abdère, et Sosicrate de Phanagon. Le treizième livre d'Athénée, les dialogues de Lucien, les lettres d'Alciphron... (Chaussard, 1801, p. 34).

${ }^{18}$ Para una presentación exhaustiva de la figura de Aspasia, ver Spinelli (2017).

${ }^{19}$ Hacia el año 350 a. C., Friné fue acusada de impiedad (asebeia), tal como a Sócrates. Friné había sido la modelo del escultor Praxíteles para su Afrodita, lo que agravaba la situación de la hetaira, al presuntamente haber personificado a la diosa. El orador Hipérides se hizo cargo de su defensa. Pero al parecer este no fue capaz de persuadir a los jueces, quienes dudaban de la inocencia de Friné. Entonces, para salvarla, Hipérides habría descubierto los pechos de Friné, con el fin de mostrar su soberbia belleza. Seducidos o atemorizados por motivos supersticiosos (temían condenar a muerte a una auténtica "sacerdotisa de Afrodita"), la eximieron. Acerca del discurso de Hipérides, ver Cooper (1995) y O’Connell (2013).
} 


\section{Natalia Zorrilla}

como Aspasia fueron acusadas de impiedad. Esta última quizás sea la más célebre de las cuatro, pues fue la pareja de Pericles hasta su muerte, en cuyas decisiones políticas habría influido. Maestra de retórica (dueña de su propia escuela), era una reconocida interlocutora en el círculo de los socráticos ${ }^{20}$. Algunos historiadores le atribuyen el haber ejercido la prostitución, pero es una alegación no comprobada. Teodora, similarmente, sería la emperatriz bizantina, esposa de Justiniano I; reinarían a la par hasta su deceso. De orígenes humildes y sacrificados, al ser nombrada emperatriz, intervino de manera activa en la política defendiendo los derechos de las mujeres ${ }^{21}$.

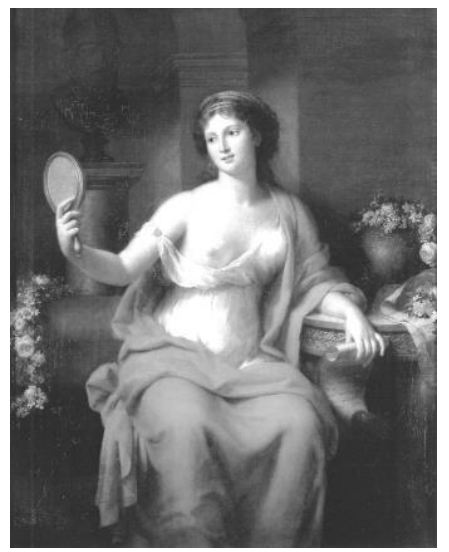

Aspasia (autorretrato como Aspasia) de Marie-Geneviève Bouliar ${ }^{22}, 1794$.

Imagen obtenida de Wikimedia Commons (dominio público) ${ }^{23}$. Musée des Beaux-Arts, Arras.

Estas cuatro mujeres encarnan la belleza, la maestría del arte erótico, son dadas a la reflexión filosófica y se conducen con una libertad inusitada que en ciertos casos pueden desarrollar en el campo de la política. ¿Qué hay entonces detrás de la elección de estos nombres? ¿Se busca meramente seguir una moda neoclásica sin más? Desde nuestro punto de vista, considerando el texto de forma integral, entendemos que la aparición de estas hetairai y personalidades femeninas célebres en la etapa de culminación de la historia de Juliette no es casual. Antes bien, se enmarca en este

\footnotetext{
${ }^{20}$ Se la menciona, por ejemplo, en el diálogo Menexeno de Platón.

${ }^{21}$ David Potter (2015) describe a Teodora como una emperatriz dedicada a acabar con la prostitución forzada, construyendo casas de refugio para aquellas mujeres que eran liberadas de tal actividad, y particularmente activa en contra de la prostitución infantil. También remarca que muchos de los contemporáneos de Teodora destacaban sus orígenes "populares" y su presunta reputación dudosa, ya que de joven habría sido bailarina y/o prostituta.

${ }^{22}$ Marie-Geneviève Bouliar (1762-1825), o también Bouliard, fue una pintora francesa contemporánea a Sade. Este retrato de Aspasia que realizó recibió el Prix d'Encouragement. Para más detalles de la vida de esta artista y su Aspasie, véase Henry (1995, pp. 91-95).

${ }^{23} \mathrm{https}$ ///commons.wikimedia.org/wiki/File:Aspasia_painting.jpg 148 | AlPHA No 53 (DiCIEMBRE 2021) PÁGS. 141-152. ISSN 07 16-4254
} 
retroceso hacia el pasado grecorromano que va viviendo progresivamente Juliette y que se da en forma paralela a la consolidación de la autonomía de la protagonista de la novela, proceso que implica plantearse, a su vez, qué es ser mujer y cómo serlo sin dejarse atrapar por todos los constreñimientos que parecerían asociarse tradicionalmente a esta identidad sexogenérica. La figura de la hetaira parecería ser ideal en este sentido, pues, a pesar de la evidente desigualdad y falta de reconocimiento de derechos respecto de los varones ciudadanos atenienses, constituye una alternativa al tradicional rol de la esposa.

\section{A MODO DE CONCLUSIÓN}

Desde el comienzo de Histoire de Juliette, las gasas y túnicas neoclásicas envuelven a la protagonista homónima ${ }^{24}$ y a sus tutoras libertinas. Esta identidad estética las distingue y las asocia a la Grecia Clásica; simboliza, entre otras cosas, su inclinación hacia la filosofía y la retórica, inclinación que está muy vinculada con su estilo de vida sexualmente libertino. A pesar de que Annie Le Brun considera que uno de los mayores talentos de Juliette consiste en la moderación de su intelectualidad (Le Brun, 2008, p. 262), este autocontrol al que se refiere la intérprete no invalida el excelso desempeño de Juliette en discusiones filosóficas y políticas. Le Brun no quiere decir con esto que Juliette no tiene un genuino interés por asuntos teóricos, sino que sabe dominar sus deseos mediante ejercicios espirituales que la misma práctica filosófica le ha facilitado. Este gesto de revestirse y rodearse de marcas y trazas neoclásicas, lejos de ser una mera moda pasajera, resulta ser, antes bien, un modo de construir la feminidad.

De hecho, los placeres del amor de los que estas mujeres libertinas gozan por fuera de la cópula matrimonial heteromonogámica entre ellas las acerca conformando cierta comunidad sáfica (ellas suelen describir su deseo por otras mujeres como saphotisme [Sade, 1998, p. 761]). A pesar de su erotismo extremadamente cruel, las parejas y las amistades que entre ellas se forman constituyen los lazos más duraderos y estables (según criterios libertinos), como sucede con Juliette y Clairwil y después con nuestra protagonista y la Durand. Se consideran además sacerdotisas de Afrodita (o Venus). El culto que le rinden a esta diosa, irónico, metafórico o literal, se desarrolla y se profundiza

\footnotetext{
${ }^{24}$ Así describe Juliette su encuentro con Mme Delbène, su primera instructora libertina: Il faisait une chaleur incroyable, et cette excessive ardeur du soleil leur servit d'excuse à l'une et à l'autre sur le désordre où je les trouvai; il était tel, qu'à cela près d'une chemise de gaze, que retenait simplement un gros noud de ruban rose, elles étaient en vérité presque nues (...). Jetant aussitôt loin d'elle les gazes qui l'enveloppaient, elle parut à nos regards belle comme la Vénus qui fixa l'hommage des Grecs (Sade, 1998, pp. 182-183). "Hacía un calor insoportable, y este ardor excesivo del sol les sirvió de excusas a ambas para el desorden en que las encontré: hasta tal punto era así que, excepto una blusa de gasa sujeta simplemente con un gran lazo rosa, estaban prácticamente desnudas (...). Tirando las gasas que la envolvían, apareció a nuestra vista bella como la Venus que inmortalizaron los griegos" (Sade, 2009, 10-11).
} 
a lo largo de la trama de la novela, llegando al punto de ofrecer sacrificios humanos en sus antiguos templos ${ }^{25}$.

En el siglo XVIII, evocar a la figura de la hetaira es abrir la posibilidad a las lectoras de pensarse bajo otro modelo femenino, que pregona la autonomía y la participación de las mujeres en las esferas intelectual y política, además de promover cierta liberación sexual, harto polémica y disruptiva en el caso de nuestra heroína Juliette debido a su naturaleza criminal. Sade no es ni ha sido leído hegemónicamente como un autor "feminista"; la obra de este sulfuroso escritor no convoca a la acción política organizada en favor de los derechos de las mujeres. Sin embargo, puede que la difusión de sus escritos haya tenido consecuencias insospechadas y que haya abierto espacios liminales de reflexión crítica acerca de lo que significa ser mujer, en particular de lo que significa experimentar placeres (y constreñimientos) sexuales en el marco de las restricciones normativas que se imponen socialmente para configurar las identidades de género. $\mathrm{O}$ bien por el contrario, puede que el gesto de servirse de un imaginario antiguo clásico para retratar a sus heroínas filósofas tenga el objetivo de producir modelos demasiado distantes y fantasiosos como para producir en sus lectoras una genuina identificación con estos personajes, evitando que se sientan reflejadas en ellas (distancia que se construye a partir del perfil criminal de estas libertinas). Sea como fuere, y quedando aun mucha gasa para cortar, las inquietantes hetairai sadeanas continuarán suscitando interrogantes e interpelando a los y las intérpretes del marqués.

\section{OBRAS CITADAS}

Abramovici, Jean-Christophe (1995). Les infortunes de la vertu. Sade. CNRS Éditions \& Zulma, Bibliothèque Nationale de France (Collection "Manuscrits").

Carter, Angela [1978] (2001). The Sadeian Woman: And the Ideology of Pornography. Penguin.

Castro, Clara (2013). Entre le crime et la sensibilité. Itinéraires 2013 (2) |2014. $\mathrm{http}: / /$ journals.openedition.org/itineraires/652.

Chaussard, Pierre (1801). Fêtes et courtisanes de la Grèce, t. IV. Chez F. Buisson.

Condomines, Anaïs (29 de mayo de 2019). Droit à la drague, cri de colère et marquis de Sade: on a assisté au procès de Sandra Muller, initiatrice de \#balancetonporc. $L C I$.

\footnotetext{
${ }^{25}$ Durante la visita a Italia de Juliette, Clairwil y Olympe, descubren lo que interpretan solía ser un templo oculto de Venus, en donde deciden sacrificar a un grupo de pescadores como una ofrenda a la diosa:-Mes amis, leur dit Olympe en italien, nous n'avons pas voulu visiter le temple de Vénus, sans offrir un sacrifice à cette déesse; voulez-vous en devenir les prêtres?-(Sade, 1998, p. 1046). "-Amigos míos -les dice Olympe en italiano-, no hemos querido visitar el templo de Venus sin ofrecer un sacrificio a esta diosa; ¿queréis ser los sacerdotes?” (Sade, 2009, p. 775). Durante la orgía, le convidan a cada una de sus víctimas un bombón que contenía un veneno mortal, con la promesa de que ayudaría a mejorar su rendimiento sexual.
}

$150 \mid$ Alpha No 53 (DicIEMBRE 2021) PÁGS. 141-152. ISSN 07 16-4254 
https://www.lci.fr/social/droit-a-la-drague-cri-de-colere-et-marquis-de-sade-ona-assiste-au-proces-de-sandra-muller-initiatrice-de-balancetonporc-me-too2122584.html

Cooper, Craig (1995). Hyperides and the trial of Phryné. Phoenix 49 (4): 303-318. Coudreuse, Anne \& Genand, Stéphanie (Eds.) (2014). Sade et les femmes. Ailleurs et autrement. Itinéraires 2013 (2) |2014. https://journals.openedition.org/itineraires/629

De Beauvoir, Simone (1972). Faut-il brûler Sade? Gallimard. (1956). El Marqués de Sade. Leviatán.

Deneuve, Catherine (14 de enero de 2018). Rien dans le texte ne prétend que le harcèlement $a$ du bon, sans quoi je ne l'aurais pas signé. Libération. https://www.liberation.fr/debats/2018/01/14/catherine-deneuve-rien-dans-letexte-ne-pretend-que-le-harcelement-a-du-bon-sans-quoi-je-ne-l-aurais_1622399 Dillon, Mathew (2003). Girls and women in Classical Greek Religion. Routledge. Dworkin, Andrea (1979). Pornography: Men Possessing Women. Penguin.

Farina, Marie-Paule (2019). Le rire de Sade. Essai de sadothérapie joyeuse. L'Harmattan, coll. Éthiques de la création.

- (2016). Sade et ses femmes. Correspondance et journal. François Bourin Éditions. García Garino, Gabriela (2009). Las heteras atenienses: su posible rol político. Revista Melibea 3: 51-68.

Gilhuly, Kate (2009). The Feminine Matrix of Sex and Gender in Classical Athens. Cambridge University Press.

Har-Peled, Misgav (26 de abril de 2018). \#BalanceTonPorc: the story behind pigs and lust. The conversation. https://theconversation.com/balancetonporc-the-storybehind-pigs-and-lust-92491

Henry, Madeleine (1995). Prisoner of History. Aspasia of Miletus and Her Biographical Tradition. Oxford University Press.

Herman, Dianne (1978). The rape culture. En J. Freeman (Ed.), Women: A feminist perspective. (pp. 41-63). Mayfield.

Heynders, Odile (31 de octubre de 2017). Harvey Weinstein, Anne Faber and \#metoo: what de Sade can teach us about abuse in society. Diggit Magazine. https://www.diggitmagazine.com/column/harvey-weinstein-anne-faber-andmetoo-what-de-sade-can-teach-us-about-abuse-society

Irigaray, Luce (1977). Françaises' ne faites plus un effort. En Ce sexe qui n'en est pas un. Minuit.

Kalouche, Fouad (2001). Apathea and Becoming Chaos in Juliette. En Ethics of Destruction: The Path Towards Multiplicity: the Cynics, Sade, and Nietzsche. S.U.N.Y.

Kennedy, Rebecca (2015). Elite Citizen Women and the Origins of the Hetaira in Classical Athens. Helios 42(1) : 61-79.

Le Brun, Annie (2008). Sade. De pronto un bloque de abismo. El cuenco de plata. 
_ (1993). Soudain un bloc d'abîme, Sade. Gallimard.

O'Connell, Peter (2013). Hyperides and Epopteia: A New Fragment of the Defense of Phryné. Greek, Roman, and Byzantine Studies 53: 90-116.

Pomeroy, Sarah (1975). Goddesses, whores, wives and slaves. Women in Classical Antiquity. Schocken Books.

Potter, David (2015). Theodora: Actress, Empress, Saint. Oxford University Press.

Sade, Donatien Alphonse François (2009). Juliette, o las prosperidades del vicio. Traducción de Pilar Calvo. Tusquets.

— (1990-1998). Euvres, Vols. I-III. Edición, introducción y notas de Michel Delon. Gallimard-Pléiade.

Spinelli, Miguel (2017). Duas mulheres de Atenas: Aspásia, a companheira de Péricles, e Xantipa, a de Sócrates. Hypnos (São Paulo) 39: 258-287. 